\title{
LA DISCRIMINACIÓN LABORAL: ANÁLISIS DE LAS PROPUESTAS CONTENIDAS EN LA INICIATIVA DE REFORMA A LA LEY FEDERAL DEL TRABAJO
}

Jorge Luis SILVA MÉNDEZ

\section{INTRODUCCIÓN}

La Encuesta Nacional de Discriminación de 2005 (END) ${ }^{1}$ reveló las percepciones de la población sobre la discriminación en nuestro país. De acuerdo con ésta, la gran mayoría de los homosexuales (94.7\%), discapacitados $(94.4 \%)$, mujeres $(94.2 \%)$, indígenas (90.8\%), adultos mayores $(88.4 \%)$ y los pertenecientes a minorías religiosas $(80.4 \%)$ opinan que en México hay discriminación por su condición. Además, una de cada tres personas pertenecientes a estos grupos manifestó haber sido discriminada en el trabajo por su condición (30\%). Tal encuesta también muestra las percepciones de aquellos que se han sentido más discriminados en su trabajo, a saber: los discapacitados (53.4\%) y los homosexuales (40.1\%), seguidos por los adultos mayores (25.1\%), las mujeres (22.8\%), las minorías religiosas $(17.2 \%)$ y los indígenas $(7.3 \%)$. Sirvan las cifras anteriores para demostrar que la discriminación, especialmente la que se da en materia laboral, ${ }^{2}$ es un problema grave que enfrenta nuestro país por lo que

1 La END realizó 1,482 encuestas globales, así como un número determinado de encuestas a subgrupos de la población que enfrentan una condición que los hace sujetos a ser discriminados: adultos mayores, indígenas, personas con discapacidad, minorías religiosas y mujeres. De acuerdo con la nota metodológica, los resultados nos permiten obtener estimaciones nacionales con una confianza de 90\%. Véase Consejo Nacional para Prevenir la Discriminación y la Secretaría de Desarrollo Social, Primera Encuesta Nacional sobre Discriminación en México, México, 2005.

2 Véase también las siguientes notas periodísticas: Ulloa, Aída, "Persiste en México la discriminación laboral, señalan especialistas”, El Universal, México, 12 de marzo de 
urgen medidas, tanto legislativas como de política pública, que persigan su erradicación.

Las autoridades mexicanas no han ignorado esta realidad. El Consejo Nacional para Prevenir la Discriminación (Conapred), la Secretaría del Trabajo y Previsión Social (STPS), y el Instituto Nacional de las Mujeres (Inmujeres) han implementado diversas medidas para enfrentar la discriminación en sus distintas dimensiones. ${ }^{3}$ En México rige, desde el 11 de junio de 2003, la Ley Federal para Prevenir y Eliminar la Discriminación, ${ }^{4}$ además de que nuestro país ha firmado una serie de instrumentos internacionales vinculantes para eliminar la discriminación en sus diferentes manifestaciones. ${ }^{5}$

El presente artículo se centra en analizar las medidas en materia de discriminación laboral que contiene la Iniciativa de Reforma a la Ley Federal del Trabajo (Iniciativa) presentada por los legisladores del Partido Acción Nacional (PAN) en marzo de este año. Además de exponer tales medidas, el manuscrito realiza una crítica de las mismas a la luz de la legislación (tanto nacional como internacional), la doctrina y la evidencia empírica disponible. Para mejorar el orden de la exposición, el presente artículo se divide en ocho apartados, cada uno de los cuales se refiere a un rubro de medidas sobre discriminación abordadas por la Iniciativa. Los titulos de los apartados son los siguientes: trabajo decente, discapacitados, madres trabajadoras, acoso y hostigamiento sexual, jornaleros agrícolas, trabajadores domésticos, trabajadores mexicanos que laboran en el extranjero y jóvenes. Al final se dan algunos comentarios que, a manera de conclusión, valoran los avances de la Iniciativa en materia de discriminación.

2008; y Olivares Alonso, Emir, "Persiste la disriminación laboral en México, reconoce la STPS", La Jornada, México, 9 de julio de 2008.

3 Las cuales serán analizadas a detalle en las diversas secciones del artículo.

4 Secretaría de Gobernación, "Ley Federal para Prevenir y Eliminar la Discriminación”, Diario Oficial de la Federación, México, 11 de junio de 2003 (última reforma publicada el 27 de noviembre de 2007). Cabe señalar que el 27 de agosto de 2008 la CONAPRED presentó un anteproyecto para modificar este ordenamiento.

5 La Convención sobre los Derechos de las Personas con Discapacidad, y la Convención sobre la Eliminación de todas las formas de Discriminación contra la Mujer, entre otras. 


\section{TRABAJO DECENTE}

Uno de los documentos de referencia del Centro Interamericano para el Desarrollo del Conocimiento en la Formación Profesional (Cinterfor), oficina de servicio técnico de la Organización Internacional del Trabajo (OIT), concluye que el trabajo decente: "es un concepto en construcción, de carácter integrativo y de profundo contenido ético". ${ }^{6} \mathrm{El}$ manuscrito agrega que la OIT ha identificado al trabajo decente con los siguientes elementos: trabajo productivo y seguro, con respeto a los derechos laborales, con ingresos adecuados, con protección social y con diálogo social, libertad sindical, negociación colectiva y participación. ${ }^{7}$

El artículo 2o. de la Iniciativa incorpora el concepto de trabajo decente a la legislación laboral, el cual tiene como uno de sus elementos fundamentales la no discriminación de los trabajadores. Siguiendo este precepto, el artículo 3o. de la Iniciativa prohíbe de forma expresa la discriminación por "motivo de origen étnico, género, preferencia sexual, edad, discapacidades, doctrina política, condición social, religión, opiniones, estado civil o cualquier otro que atente contra la dignidad humana". ${ }^{8}$ Esto representa un cambio notable con respecto a lo que señala en artículo 30. de la Ley Federal del Trabajo (LFT), el cual sólo prohíbe la discriminación por motivos de raza, sexo, edad, credo religioso, doctrina política o

6 Cinterfor, Formación para el trabajo decente, documento en línea, véase http:// www.cinterfor.org.uy/public/spanish/region/ampro/cinterfor/rct/35rct/doc_ref/doc $1 / i$. htm, fecha de consulta: 19 de abril de 2010. Un breve recuento del concepto de trabajo decente también se hace en Espinoza, Malva, Trabajo decente y protección social, Santiago, OIT, 2003, pp. 4-6.

7 El documento de la OIT que trata por primera vez el tema del trabajo decente, establece lo siguiente: "No se trata simplemente de crear puestos de trabajo, sino que han de ser de una calidad aceptable. No cabe disociar la cantidad del empleo de su calidad. Todas las sociedades tienen su propia idea de lo que es un trabajo decente...". Véase OIT, Trabajo decente, memoria del director general de la 87a. reunión de la Conferencia Internacional del Trabajo, Ginebra, junio de 1999, documento en línea http://www.oit. org/public/spanish/standards/relm/ilc/ilc87/rep-i.htm, fecha de consulta: 19 de abril de 2010 .

8 El artículo 3o. de la Iniciativa también establece que no se considerarán discriminatorias las distinciones, exclusiones o preferencias que se sustenten en las calificaciones particulares que exija una labor determinada. 
condición social. ${ }^{9}$ Los artículos 20 . y 3o. son propuestas que enriquecen a los principios generales del derecho laboral mexicano, pues enuncian de forma expresa una mayor cantidad de causales a partir de las que puede derivar una conducta discriminatoria en materia laboral, lo cual lleva a que la Iniciativa cumpla, de una mejor manera que la LFT vigente, el mandato de reglamentar el principio de no discriminación señalado en el tercer párrafo del artículo 1o. de la CPEUM. ${ }^{10}$

\section{DISCAPACITADOS}

En el 2001, la OIT emitió un documento que enlista varias recomendaciones prácticas sobre la gestión de las discapacidades en el lugar de trabajo. ${ }^{11}$ Con base en lo que dicta el Convenio número $159^{12}$ y la Recomendación número $168,{ }^{13}$ tal escrito presenta una serie de medidas que se deben tomar en cuenta para administrar de mejor manera los establecimientos en los que laboran personas discapacitadas. ${ }^{14}$ Las recomendaciones se agrupan en siete apartados: obligaciones generales de los empleadores, de los representantes de los trabajadores y responsabilidades de las autoridades competentes, sistema de gestión de las cuestiones re-

9 El artículo 56 de la Iniciativa señala que las condiciones de trabajo deben ser proporcionales a la importancia de los servicios, sin que pueda haber diferencias por motivos de discriminación.

10 "Queda prohibida toda discriminación motivada por origen étnico o nacional, el género, la edad, las discapacidades, la condición social, las condiciones de salud, la religión, las opiniones, las preferencias, el estado civil o cualquier otra que atente contra la dignidad humana y tenga por objeto anular o menoscabar los derechos y libertades de las personas".

11 OIT, Repertorio de recomendaciones prácticas sobre la gestión de las discapacidades en el lugar de trabajo, Reunión tripartita de expertos sobre la gestión de las discapacidades en el lugar de trabajo, Ginebra, octubre 2001.

12 OIT, Convenio núm. 159 sobre la readaptación profesional y el empleo de personas Inválidas, adoptado el 20 de junio de 1983 (decreto promulgatorio publicado en el Diario Oficial de la Federación el 22 de abril de 2002).

13 OIT, Recomendación núm. 168 de la OIT sobre la readaptación profesional y el empleo de personas inválidas, 1983.

14 Se define a una persona discapacitada como "un individuo cuyas posibilidades de obtener empleo, reintegrarse al empleo y conservar un empleo adecuado, así como de progresar en el mismo, resulten considerablemente reducidas como consecuencia de una disminución física, sensorial, intelectual o mental debidamente reconocida", idem. 
lativas a las discapacidades, contratación, promoción, conservación del empleo, cambios y confidencialidad.

De las recomendaciones anotadas, la Iniciativa sólo retoma la obligación patronal de establecer un acceso y un espacio de trabajo adecuados para el personal discapacitado. La fracción XVI bis del artículo 132 contempla que aquellos centros de trabajo que tengan más de 50 trabajadores deben contar con instalaciones adecuadas para el acceso y desarrollo de actividades de las personas con discapacidad. El segundo artículo transitorio contempla que, en caso de aprobarse la Iniciativa, el patrón tendrá 36 meses para realizar las adecuaciones pertinentes a las instalaciones de los centros de trabajo.

La Iniciativa también queda corta con respecto a lo establecido en otro instrumento internacional: la Convención de Naciones Unidas sobre los Derechos de las Personas con Discapacidad (CNUDPD), instrumento de carácter vinculante para nuestro país. ${ }^{15} \mathrm{El}$ artículo 9.1.a de la CNUDPD establece que los estados partes deberán adoptar medidas pertinentes para asegurar el acceso de las personas con discapacidad a sus lugares de trabajo. Este sería el único aspecto que, como hemos anotado, retoma la Iniciativa. Sin embargo, deja de lado el artículo 27 que enumera varias obligaciones de los estados partes relativas al trabajo y empleo de los discapacitados, entre otras, el asegurar que las personas con discapacidad puedan ejercer sus derechos laborales y sindicales en igualdad de condiciones con los demás, y el permitir que las personas con discapacidad tengan acceso efectivo a programas generales de orientación técnica y vocacional, servicios de colocación y formación profesional continua, entre otras.

Hay que mencionar que el Estado mexicano ha tratado de cumplir con sus compromisos internacionales en materia de discriminación laboral

15 Organización de las Naciones Unidas (ONU), Convención sobre los Derechos de las Personas con Discapacidad, adoptado el 13 de diciembre de 2006 (decreto promulgatorio publicado en el Diario Oficial de la Federación el 2 de mayo de 2008); véase González Martín, Nuria, "Convención de Naciones Unidas sobre los Derechos de las Personas con Discapacidad", Boletín Mexicano de Derecho Comparado, México, Instituto de Investigaciones Jurídicas, UNAM, nueva serie, año XL, núm. 120, septiembrediciembre de 2007, pp. 951-961; y González Martín, Nuria, "Convención de Naciones Unidas sobre los Derechos de las Personas con Discapacidad", Anuario Mexicano de Derecho Internacional, México, Instituto de Investigaciones Jurídicas, UNAM, 2008, vol. VIII, pp. 527-540. 
por discapacidad a partir de diversas medidas legislativas ${ }^{16}$ y de política pública; ${ }^{17}$ sin embargo, la Iniciativa no incorpora de manera expresa muchos de los preceptos contenidos en los tratados/recomendaciones internacionales, lo que deja mucho que desear de una propuesta de ley que busca "la no discriminación en las relaciones laborales".

\section{MADRES TRABAJADORAS}

Las trabajadoras gozan de una garantía social que protege su maternidad, esto es, su embarazo, parto y puerperio, ${ }^{18}$ la cual se consagra en el artículo 123, apartado A fracción V de la CPEUM. ${ }^{19}$ El artículo 170 de LFT replica el contenido de tal precepto constitucional. ${ }^{20}$ La Iniciati-

16 Destaca el artículo 23 del Reglamento Federal de Seguridad, Higiene y Medio Ambiente de Trabajo, así como el artículo 7.1.3 de la norma oficial mexicana NOM-001STPS-2008, véase STPS, "Reglamento Federal de Seguridad, Higiene y Medio Ambiente de Trabajo", Diario Oficial de la Federación, México, 21 de enero de 1997; STPS, "Norma oficial mexicana NOM-001-STPS-2008, edificios, locales, instalaciones y áreas en los centros de trabajo-Condiciones de seguridad", Diario Oficial de la Federación, México, 24 de noviembre de 2008.

17 Destacan los programas impulsados por la STPS y el DIF, tales como Abriendo Espacios, el Programa de Atención a Personas con Discapacidad, etcétera. Para una breve descripción de estos programas, véase Herrera Gómez, María Guadalupe, Costos e impacto de la discriminación laboral hacia personas con discapacidad: mecanismos de inclusión y políticas públicas, México, Conapred, documento de trabajo núm. E-152007, 2007, pp. 56-62.

18 Véase el artículo 61 fracción de la Ley General de Salud, así como Kurczyn Villalobos, Patricia, Acoso sexual y discriminación por maternidad en el trabajo, México, Instituto de Investigaciones Jurídicas, UNAM, 2004, serie doctrina jurídica, núm. 172, p. 121 y 122 .

19 Que a la letra dice: "Las mujeres durante el embarazo no realizarán trabajos que exijan un esfuerzo considerable y signifiquen un peligro para su salud en relación con la gestación; gozarán forzosamente de un descanso de seis semanas anteriores a la fecha fijada aproximadamente para el parto y seis semanas posteriores al mismo, debiendo percibir su salario íntegro y conservar su empleo y los derechos que hubieren adquirido por la relación de trabajo. En el período de lactancia tendrán dos descansos extraordinarios por día, de media hora cada uno para alimentar a sus hijos".

20 Recordemos que el título quinto de la LFT establece diversas disposiciones aplicables en el caso del trabajo de las mujeres. Además, existen una serie de reglamentos que también gobiernan el trabajo de la mujer; por ejemplo, del artículo 153 al 157 del Reglamento Federal de Seguridad, Higiene y Medio Ambiente de Trabajo. 
va propone dos cambios a este artículo. Primero, la trabajadora tiene el derecho a solicitar que se le transfieran hasta cuatro de las seis semanas de descanso previas al parto para después del mismo; ${ }^{21}$ y segundo, bajo ciertas circunstancias, la trabajadora puede intercambiar sus reposos extraordinarios para la lactancia por una reducción en su jornada de trabajo. ${ }^{22}$ Sin embargo, ambas propuestas tienen el mismo defecto: la trabajadora requiere de la anuencia del patrón para poder ejercer su derecho. Consideramos que el condicionar el ejercicio de estas prerrogativas a la voluntad del patrón traería como resultado que tales derechos se usaran con poca frecuencia. Además, pensamos que tal condicionamiento va en contra del espíritu de diversos acuerdos contenidos en instrumentos internacionales vinculantes para nuestro país, tales como el artículo 25.2 de la Declaración de los Derechos del Hombre (DDH), ${ }^{23}$ el artículo 11.1.f de la Convención sobre Eliminación de Todas las Formas de Discriminación en Contra de las Mujeres (CEDM), ${ }^{24}$ y el artículo 18.2 de la Convención de los Derechos de los Niños (CDN). ${ }^{25}$

Pero la Iniciativa hace contribuciones valiosas a la protección de los derechos maternos. Mientras la LFT sólo establece de forma implícita la prohibición de exigir la renuncia a causa del embarazo, puerperio, lactancia, estado civil o responsabilidades familiares, así como la prohibición de cancelar cualquiera de los derechos laborales o de seguridad social

21 Artículo 170 fracción II.

22 Artículo 170 fracción IV.

23 "La maternidad y la infancia tienen derecho a cuidados y asistencia especiales. Todos los niños, nacidos de matrimonio o fuera de matrimonio, tienen derecho a igual protección social”. Véase ONU, Declaración Universal de Derechos Humanos, adoptada el 10 de diciembre de 1948.

24 "El derecho a la protección de la salud y a la seguridad en las condiciones de trabajo, incluso la salvaguardia de la función de reproducción". Véase ONU, Convención sobre la Eliminación de todas las formas de Discriminación contra la Mujer, adoptada el 18 de diciembre de 1979 (decreto promulgatorio publicado en el Diario Oficial de la Federación el 12 de mayo de 1981).

25 "A efectos de garantizar y promover los derechos enunciados en la presente Convención, los Estados partes prestarán la asistencia apropiada a los padres y a los representantes legales para el desempeño de sus funciones en lo que respecta a la crianza del niño y velarán por la creación de instituciones, instalaciones y servicios para el cuidado de los niños". Véase ONU, Convención sobre los Derechos del Niño, adoptada el 20 de noviembre de 1989 (decreto promulgatorio publicado en el Diario Oficial de la Federación el 25 de enero de 1991). 
que le corresponden a las madres trabajadoras, ${ }^{26}$ la Iniciativa incorpora ambas prohibiciones al cuerpo de la ley. Así, el patrón tiene prohibido exigir la presentación de certificados médicos de ingravidez para el ingreso, permanencia o ascenso en el empleo; ${ }^{27}$ y también tiene prohibido despedir a una trabajadora o coaccionarla directa o indirectamente para que renuncie por estar embarazada, por cambio de estado civil o por tener al cuidado hijos menores. ${ }^{28}$ Para velar por el efectivo cumplimiento de estas propuestas, la Iniciativa contempla una multa equivalente de 50 a 2,500 veces el salario mínimo general para aquellos que la quebranten. ${ }^{29}$ Además, la Iniciativa propone que el patrón esté obligado a apoyar a la autoridad competente a asegurar el pago de las pensiones alimenticias. ${ }^{30}$

Finalmente, plantea medidas para proteger a la madre trabajadora en caso de una contingencia sanitaria. En estos casos, no podrá utilizarse el trabajo de mujeres en periodos de gestación o de lactancia, sin que las trabajadoras pierdan derecho alguno (especialmente el pago de su salario). ${ }^{31}$ Creemos que esta medida es sumamente pertinente, pues atiende un escenario que vivimos recientemente en nuestro país: la epidemia de la influenza $\mathrm{A}(\mathrm{H} 1 \mathrm{~N} 1)$, y que puso en riesgo la salud pública, en especial la de los lactantes, infantes y adultos mayores. De acuerdo a un reporte de la Secretaría de Salud del 14 de abril de 2010, ${ }^{32}$ se tenían con-

26 Lo cual se deriva de la interpretación armónica de lo establecido en los artículos 51 fracción IX, 132 fracción XXVII y 18 de la LFT. Véase también: Kurczyn, op. cit., nota 18 , p. 140.

27 Artículo 133 fracción XIV.

28 Artículo 133 fracción XV.

29 Artículo 995. Por supuesto, la comprobación de tales conductas discriminatorias ilegales por parte del patrón darían a la trabajadora el derecho de rescindir la relación laboral y solicitar la indemnización correspondiente (artículo 51 fracción X de la Iniciativa).

30 El artículo 123 fracción XXIII bis, obliga al patrón a hacer las deducciones y pagos correspondientes a las pensiones alimenticias y, a la par, el artículo 110 fracción $V$ señala que el patrón debe notificar a la autoridad competente y a los acreedores alimentarios, en un tiempo máximo de cinco días, del momento en que el trabajador deje de prestar sus servicios. Véase como referencia los artículos 97 fracción I, 110 fracción V y 112 de la LFT.

31 Artículo 168.

32 Secretaría de Salud, Situación actual de la epidemia (al 14 de abril de 2010), documento en línea, http://portal.salud.gob.mx/contenidos/noticias/influenza/estadisticas. html, consultada el 19 de abril de 2010. 
firmados 72,462 casos y 1,185 defunciones. La información nos indica que 7,865 casos $(10.85 \%)$ y 69 decesos $(5.8 \%)$ corresponden a menores de entre 0 a 4 años.

\section{ACOSO Y HOSTIGAMIENTO SEXUAL}

Una encuesta realizada por el Inmujeres y la Secretaría de la Función Pública a 258 dependencias de la administración pública federal detectó 25,728 casos de abuso sexual y 7,796 denuncias ante las autoridades y mecanismos competentes. El 15\% de las mujeres y el 5.3\% de los hombres reportaron haber sido víctimas de acoso sexual. Ocho de cada diez personas encuestadas manifestaron que es necesario contar con mecanismos para proteger a las mujeres y a los hombres del hostigamiento y acoso sexual. ${ }^{33} \mathrm{~A}$ la luz de los datos anteriores, podemos aseverar que el acoso y el hostigamiento sexual ocurren con cierta frecuencia en los centros de trabajo, tanto de empresas privadas como de entidades gubernamentales. ${ }^{34}$

La Recomendación General número 19 del Comité para la Eliminación de la Discriminación contra la Mujer ${ }^{35}$ condena las prácticas de hostigamiento sexual y exhorta a los estados parte a tomar medidas para solucionar tal cuestión. Cabe señalar que, a pesar de la preocupación de

33 Secretaría de Relaciones Exteriores, "Presentan el Protocolo de Intervención para Casos de Hostigamiento y Acoso Sexual", Comunicado de prensa núm. 102, 7 de abril de 2010. Además, véase Inmujeres, Instituto Nacional de Estadística y Geografía y Fondo de Naciones Unidas para el Desarrollo de la Mujer, Encuesta Nacional sobre la Dinámica de las Relaciones en los Hogares 2006, México, 2006. Disponible en http:// www.inegi.org.mx/est/contenidos/espanol/proyectos/metadatos/encuestas/endrh_231. $a s p ? s=e s t \& c=11219$, consultada el 19 de abril de 2010. Esta encuesta también se realizó en 2003 y en 199.

34 Kurczyn, op. cit., nota 18, pp. 59-102.

35 Comité de las Naciones Unidas para la Eliminación de la Discriminación contra la Mujer, Recomendación General núm. 19 sobre la Violencia contra la Mujer, 1992. Tal documento define el hostigamiento sexual de la siguiente forma: "El hostigamiento sexual incluye un comportamiento de tono sexual tal como contactos físicos e insinuaciones, observaciones de tipo sexual, exhibición de pornografía y exigencias sexuales, verbales o de hecho. Este tipo de conducta puede ser humillante y puede constituir un problema de salud y de seguridad; es discriminatoria cuando la mujer tiene motivos suficientes para creer que su negativa podría causarle problemas en el trabajo, en la contratación o el ascenso inclusive, o cuando crea un medio de trabajo hostil." 
la comunidad internacional por la comisión de este tipo de conductas, no hay ningún convenio internacional vinculante en tal materia. ${ }^{36} \mathrm{El}$ hostigamiento y el acoso sexual son considerados delitos por la legislación penal, tal es el caso de los artículos 259 bis del Código Penal de la Federación ${ }^{37}$ y el 179 del Código Penal para el Distrito Federal. ${ }^{38}$ Sin que éste sea el lugar para criticar las normas citadas, ${ }^{39}$ éstas constituyen referencias legales que nos acercan al significado legal del hostigamiento y del acoso sexual en nuestro país.

La LFT no define ninguna de estas dos conductas, ni tampoco establece sanciones precisas para los patrones y trabajadores que las comenten. A pesar de que las víctimas del hostigamiento/acoso sexual en el trabajo pueden iniciar acciones legales en contra de sus ofensores vía laboral, es posible que el procedimiento sea complicado debido a la oscuridad de la norma..$^{40}$ Por supuesto que la redacción actual de la LFT da lugar a que

36 Cinterfor, El acoso sexual, un problema de relaciones de poder, documento en línea, http://www.cinterfor.org.uy/public/spanish/region/ampro/cinterfor/temas/gender/ doc/cinter/pacto/cue_gen/aco_sex.htm, consultada el 17 de abril de 2010.

37 "Al que con fines lascivos asedie reiteradamente a persona de cualquier sexo, valiéndose de su posición jerárquica derivada de sus relaciones laborales, docentes, domésticas o cualquiera otra que implique subordinación, se le impondrá sanción de hasta cuarenta días de multa. Si el hostigador fuese servidor público y utilizase medios o circunstancias que el cargo le proporcione, se le destituirá de su cargo. Solamente será punible el hostigamiento sexual, cuando se cause un perjuicio o daño. Sólo se procederá contra el hostigador, a petición de la parte ofendida".

38 "Al que acose sexualmente con la amenaza de causarle a la víctima un mal relacionado respecto a la actividad que los vincule, se le impondrá de seis meses a tres años de prisión. Si el hostigador fuese servidor público y se aprovechare de esa circunstancia, además de la pena prevista en el párrafo anterior, se le impondrá destitución por un lapso igual al de la pena de prisión impuesta. Este delito se perseguirá por querella.”

39 Kurzcyn, op. cit., nota 18, pp. 62-64.

40 Por ejemplo, una mujer cuyo patrón la acosa sexualmente podría rescindir la relación de trabajo alegando que el patrón incurrió en una falta de probidad u honradez en su contra (su reclamo se basaría en lo establecido en el artículo 51 fracción II). La Junta, siguiendo su obligación de dictar el laudo a verdad sabida, y buena fe guardada y apreciando los hechos en conciencia (artículo 841 de la LFT) podría condenar al patrón al pago de la indemnización correspondiente por la comisión de tales conductas, si es que así lo indican las pruebas respectivas. Note que la jurisprudencia entiende por "falta de probidad u honradez" el que el trabajador no proceda rectamente en las funciones encomendadas, con mengua de rectitud de ánimo, o sea, que se aparte de las obligaciones que se tienen a cargo procediendo en contra de las mismas, dejando de hacer lo que se tiene encomendado, o haciéndolo en contra. Véase Poder Judicial de la Federación, "Pro- 
la Junta, al resolver este tipo de reclamos, deba aplicar su facultad discrecional, y eventualmente no condenar al patrón debido a la falta de un estándar legal preciso. Lo mismo podría ocurrir cuando un compañero de trabajo acosa u hostiga sexualmente a otro.

La Iniciativa propone medidas para regular estas conductas. En primer lugar, define de manera precisa los términos de hostigamiento sexual y de abuso sexual. ${ }^{41}$ En segundo lugar, propone que la relación laboral con aquellos trabajadores que cometan actos de hostigamiento o acoso sexual sea rescindida sin responsabilidad para el patrón, ${ }^{42}$ y además prohíbe que los patrones o sus representantes cometan, permitan o toleren actos de hostigamiento o abuso sexual en contra de cualquier persona en el lugar de trabajo. ${ }^{43}$ Asimismo, contempla una multa de 250 a 5,000 veces el salario mínimo general al que realice, tolere o permita actos de hostigamiento sexual en contra de sus trabajadores. ${ }^{44}$

\section{JORNALEROS AGRÍCOLAS}

Aunque la Iniciativa no lo precisa, consideramos que las reformas relativas a los jornaleros agrícolas guardan una relación especial con la

bidad u honradez, falta de. Concepto", jurisprudencia, séptima época, cuarta sala de la Suprema Corte de Justicia de la Nación, Apéndice de 1995, México, t. V, p. 260, y Poder Judicial de la Federación, "Probidad u honradez, falta de.", aislada, novena época, Primer Tribunal Colegiado del décimo quinto circuito, Semanario Judicial de la Federación y su Gaceta, México, septiembre de 1998, t. VIII, p. 1193.

41 Se define al acoso sexual como "una forma de violencia en la que, si bien no existe la subordinación, hay un ejercicio abusivo del poder que conlleva a un estado de indefensión y de riesgo para la víctima, independientemente de que se realice en uno o varios eventos" (segundo párrafo del artículo 135 fracción XI) y al hostigamiento sexual como "el ejercicio del poder en una relación de subordinación real de la víctima frente al agresor en el ámbito laboral, que se expresa en conductas verbales, físicas o ambas, relacionadas con la sexualidad de connotación lasciva" (segundo párrafo del artículo 133 fracción XIII).

42 Artículo 47 fracción VIII. Hay que considerar que la redacción del mismo precepto en la LFT se limita a establecer como causal de rescisión la comisión de "actos inmorales". En este sentido, la propuesta de la Iniciativa deja fuera de duda que aquel trabajador que hostiga o acosa sexualmente estará expuesto a perder su fuente de trabajo sin recibir indemnización alguna.

43 Artículo 133 fracciones XII y XIII.

44 Artículo 994 fracción VI. 
discriminación a los trabajadores indígenas. El artículo 20 del Convenio número 169 sobre Pueblos Indígenas y Tribales en Países Independientes (Convenio 169) regula la contratación y condiciones de empleo de estos trabajadores. ${ }^{45}$ De especial relevancia resultan los incisos 2) y 3 ) de dicho precepto. El inciso 2) establece que los gobiernos deberán hacer cuanto esté en su poder para evitar cualquier discriminación entre los trabajadores pertenecientes a los pueblos indígenas y los demás trabajadores, en especial en lo relativo al acceso al empleo, la remuneración al trabajo, la asistencia médica y social, la seguridad e higiene en el trabajo, así como al derecho de asociación. El inciso 3) enuncia que las medidas adoptadas deberán garantizar que los trabajadores estacionales empleados en la agricultura gocen de la protección que confiere la legislación laboral, que no estén sometidos a condiciones de trabajo peligrosas para su salud, que no estén sujetos a sistemas de contratación coercitivos y que gocen de igualdad de oportunidades y de trato.

Las propuestas que hace la Iniciativa para modificar el contenido del capítulo VIII del título sexto incorporan varios de los preceptos contenidos en los incisos referidos del Convenio 169. El artículo 279 da una nueva definición para los trabajadores de campo, siendo éstos aquellas personas que son contratadas para labores de siembra, deshije, cosecha, recolección, preparación de productos para su primera enajenación y otras de análoga naturaleza agrícola, ganadera, forestal o mixta, a cielo abierto o en invernadero. Tal definición es mucho más precisa que la que establece la LFT, la cual se refiere tanto a estos trabajadores como aquellos que "ejecutan los trabajos propios y habituales de la agricultura, de la ganadería y forestales, al servicio de un patrón". El artículo 280 establece de forma expresa que el patrón estará obligado a llevar un registro de los trabajadores eventuales, el cual además deberá remitir al Instituto Mexicano del Seguro Social. Los artículos 281, 282, 283 y 284 enlistan una serie de obligaciones y prohibiciones a los patrones, las cuales no se encuentran de forma explícita en la LFT vigente; por ejemplo, la obligación del patrón de proporcionar agua potable durante la jornada de trabajo, la de fomentar la creación de cooperativas de consumo entre los

45 OIT, Convenio núm. 169 sobre Pueblos Indígenas y Tribales en Países Independientes, adoptado el 27 de junio de 1989 (decreto promulgatorio publicado en el Diario Oficial de la Federación el 24 de enero de 1991). 
trabajadores, la de fomentar la alfabetización entre los trabajadores y sus familiares, etcétera.

\section{TRABAJADORES DOMÉSTICOS}

En marzo de 2010, el Inmujeres señaló que "las trabajadoras domésticas enfrentan discriminación racial, explotación, prolongadas jornadas de trabajo, bajos salarios, inseguridad en el empleo, hostigamiento sexual y diversas formas de violencia que atentan no sólo contra derechos laborales, sino con su dignidad". ${ }^{46}$ La misma fuente hace referencia a datos de la Encuesta Nacional de Ocupación y Empleo, y menciona que casi el $11 \%$ de las trabajadoras ocupadas son empleadas domésticas, esto es, alrededor de 1,720,450 mujeres.

En 2008 la Confederación Sindical Internacional solicitó a los gobiernos de los países que forman la OIT que apoyaran una propuesta para hacer un convenio internacional que abordara de manera específica la protección laboral de los trabajadores domésticos. ${ }^{47}$ La OIT señaló, a finales del mismo año, su intención de "preparar la acción normativa" que pueda remediar los problemas de este tipo de trabajadores. ${ }^{48} \mathrm{El}$ tema ya se encuentra inscrito en el orden del día de la reunión de 2010 de la Conferencia Internacional de Trabajo, y es de esperarse la promoción de un convenio complementado por una recomendación. La preocupación de la OIT es válida, y nace de reconocer las pobres condiciones laborales que enfrentan los domésticos. ${ }^{49}$

En 2008, la Cámara de Diputados de la LX Legislatura publicó un documento que describe el contenido de una iniciativa que pretendía mo-

46 Véase Morales, Alberto, "Inmujeres: ley descuida a empleadas domésticas", El Universal, México, 28 de marzo de 2010; y Alcántara, Verónica, "Inmujeres: Costaría servicio doméstico 30 mil pesos al mes", El Universal, México, 5 de septiembre de 2003.

47 Confederación Sindical Internacional, Protección de los trabajadores y trabajadoras domésticos: la CSI respalda una propuesta para que se haga un convenio internacional de la OIT, documento en línea, http://www.ituc-csi.org/proteccion-de-los-trabajadores-y.html? lang=es, consultada el 17 de abril de 2007.

48 Cunniah, Dan, "Editorial”, Educación Obrera, Ginebra, OIT, 2008, núm. 148-149, p. VI.

49 Demaret, Luc, "Un trabajo decente para los trabajadores domésticos: hacia un convenio internacional", ibidem, p. 6. 
dificar los artículos de la LFT que regulan el trabajo doméstico. ${ }^{50} \mathrm{La}$ iniciativa, presentada el 8 de noviembre de 2007 al pleno de la Cámara de Diputados, además de considerar diversas mejorías a las condiciones de trabajo, también abordaba otros aspectos relativos a la no discriminación de este tipo de trabajadores, a la obligación del patrón de inscribirlos al seguro social y establecía sanciones para los patrones que quebrantaran la ley.

Tomando en cuenta los elementos expuestos en los párrafos anteriores, revisemos los cambios que propone la Iniciativa en esta materia. Se pretende cambiar la redacción de tres artículos que se encuentran en el capítulo XII del título sexto, el cual regula a los trabajadores domésticos, a saber: 333, 336 y 337 fracción II. El artículo 333 establece que los trabajadores domésticos que habitan el hogar donde prestan sus servicios deberán disfrutar de un descanso mínimo diario nocturno de nueve horas consecutivas, además de un descanso mínimo diario de tres horas entre las actividades matutinas y vespertinas. La LFT se limita a aseverar que "los trabajadores domésticos deberán disfrutar de reposos suficientes para tomar sus alimentos y de descanso durante la noche". El artículo 336 otorga a los trabajadores domésticos el derecho a un descanso semanal de día y medio ininterrumpido, preferiblemente en sábado y domingo; además, establece que las partes podrán acordar la acumulación de los medios días en periodos de dos semanas, pero siempre respetando el disfrute de un día completo de descanso en cada semana. En cambio, la LFT regula los descansos de los trabajadores domésticos siguiendo las regla general; esto es, por cada seis días de trabajo, el trabajador tendrá derecho a disfrutar, al menos, de un día de descanso con goce de sueldo. El artículo 337 fracción II establece que el patrón estará obligado a proporcionar al trabajador una habitación cómoda e higiénica, alimentación sana y suficiente, y condiciones de trabajo que aseguren la vida y la salud. La LFT, en el mismo precepto, no hace referencia a una "habitación", sino a un "local", y no se refiere a la alimentación con los adjetivos de "sana y suficiente", sino con los adjetivos de "sana y satisfactoria".

Consideramos que las propuestas de la Iniciativa son insuficientes, pues sólo abordan aspectos relativos a las condiciones de trabajo de los

50 Centro de Estudios para el Adelanto de las Mujeres y la Equidad de Género, Necesidades legislativas para acceder a la regulación de las trabajadoras domésticas, México, Cámara de Diputados LX Legislatura, pp. 14-23. 
domésticos, y se deja de lado la inclusión de disposiciones que establezcan la obligación del patrón de inscribir al trabajador al seguro social, o bien, la prohibición expresa de discriminarlas. ${ }^{51}$

\section{TRABAJADORES MEXICANOS QUE LABORAN EN EL EXTRANJERO}

Datos de la Encuesta Nacional de Ocupación y Empleo al cuarto trimestre de 2009 señalan que al último trimestre de 2009 se reportó una tasa de cinco emigrantes al extranjero por cada mil residentes habituales en el territorio nacional, cifra que no ha tenido cambios desde el cuarto trimestre de 2008. Este dato contrasta con la tasa de inmigración, que es sólo de tres inmigrantes por cada mil habitantes. ${ }^{52}$ Los datos anteriores hacen constar la emigración a otro país de trabajadores mexicanos en edad productiva. ${ }^{53}$ Aunque parte de éstos se trasladan a otros países de manera ilegal para trabajar, hay quienes viajan, incluso, con un contrato de trabajo debidamente reconocido por las leyes mexicanas y/o los tratados internacionales, especialmente bajo el amparo del Tratado de Libre Comercio de América del Norte (TLCAN). Un estudio que analiza la migración de trabajadores mexicanos a los Estados Unidos menciona que los migrantes mexicanos en el periodo que va de 2000 a 2005 se han insertado en los sectores laborales de mayor precarización, como la agricultura, el servicio doméstico y de limpieza, la construcción, o bien

51 Esto es, no se incluye dentro del capítulo relativo a este trabajo especial una prohibición expresa al patrón de discriminar a este tipo de trabajadores. No ignoramos el hecho de que la Iniciativa contempla, en otras partes, la obligación que tiene el patrón de no discriminar y las multas a las que se puede hacer acreedor por hacerlo. Sin embargo, creemos que una disposición expresa inserta en este capítulo no sería redundante, sino que haría hincapié en la prohibición de una conducta que ocurre con frecuencia dadas las características del trabajo desempeñado.

52 Instituto Nacional de Estadística y Geografía, La migración internacional mexicana predominantemente en edades productivas, Comunicado núm. 107/10, México, 15 de abril de 2010, p. 1.

53 Poco más de la mitad de los migrantes reportados entre el primer trimestre de 2006 y hasta el primer trimestre de 2009 se encontraban entre los 20 y los 39 años de edad. Idem. 
en empresas manufactureras que ven al migrante mexicano como una opción de contratación a bajo costo. ${ }^{54}$

La Iniciativa plantea la modificación del artículo 28 de la LFT, el cual regula la relación laboral de los trabajadores mexicanos contratados en el territorio nacional y cuyo contrato de trabajo se rige por la ley laboral mexicana. De acuerdo con la Iniciativa, el patrón sólo está obligado a pagar los gastos de repatriación, mientras que la ley actual señala que: "Los gastos de transporte, repatriación, traslado hasta el lugar de origen y alimentación del trabajador y de su familia, en su caso, y todos los que se originen por el paso de las fronteras y cumplimiento de las disposiciones sobre migración, o por cualquier otro concepto semejante, serán por cuenta exclusiva del patrón...". Además, la Iniciativa elimina completamente la fracción I de la LFT, la cual establece que: "El trabajador tendrá derecho a las prestaciones que otorguen las instituciones de seguridad y previsión social a los extranjeros en el país al que vaya a prestar sus servicios...”. Finalmente, la fracción III de la Iniciativa exime al patrón del pago de la fianza respectiva en caso de que cuente con un establecimiento permanente y domicilio fiscal o de representación comercial en México; en cambio, la fracción III del artículo 28 de la LFT da a la Junta Local de Conciliación y Arbitraje la facultad de determinar la fianza una vez que ha verificado las estipulaciones del contrato. Esto es, la LFT no exime al patrón del pago de la fianza. ${ }^{55}$

Para promover las mejores condiciones de contratación de mexicanos en el extranjero, la Iniciativa propone la creación de dos nuevos artículos: el 28-A y el 28-B. El primero sienta las bases para la contratación de trabajadores mexicanos que son empleados en el extranjero en virtud de un acuerdo internacional. El segundo establece las normas conforme a las cuales deben operar las agencias que recluten trabajadores mexicanos para un empleo en el exterior. Tal vez el punto más sobresaliente de ambos preceptos sea la intervención de las autoridades mexicanas para verificar ciertos requisitos que deben cumplir los acuerdos de contrata-

54 Delgado Wise, Raúl y Márquez Covarrubias, Humberto, "Para entender la migración a Estados Unidos. El papel de la fuerza de trabajo barata mexicana en el mercado laboral transnacional", Problemas del Desarrollo, Revista Latinoamericana de Economía, México, UNAM, 2007, vol. 38, núm. 149, pp. 26 y 27.

55 Otra diferencia es que la Iniciativa da a la JFCA la facultad exclusiva para revisar estos contratos, mientras que la LFT concede tales facultades a las Juntas Locales de Conciliación y Arbitraje. 
ción, así como la ejecución de las reglas de operación por parte de las agencias.

De acuerdo con la exposición de motivos de la propia Iniciativa, estos tres artículos $(28,28-\mathrm{A}$ y $28-\mathrm{B})$ buscan combatir prácticas irregulares de contratación y otorgar mayor protección y seguridad jurídica a los mexicanos que van a laborar en el extranjero.

Sin que éste sea el lugar para discutir a fondo el tema, queda por ver si los artículos 28-A y 28-B violan de alguna forma el principio establecido en el artículo 42 del Acuerdo de Cooperación Laboral para América del Norte entre el gobierno de los Estados Unidos Mexicanos, el gobierno de Canadá y el gobierno de los Estados Unidos de América (ACLAN), el cual señala que: "Ninguna disposición en este Acuerdo se interpretará en el sentido de otorgar derecho a las autoridades de una de las Partes a llevar a cabo actividades de aplicación de su legislación laboral en territorio de otra Parte". A nuestro juicio el 28-A y el 28-B sólo proponen una intervención más activa de las autoridades laborales mexicanas en la fase previa a la firma del contrato de trabajo con el fin de que éstas puedan verificar que las condiciones de trabajo sean dignas. Aunque el 28-A y el 28-B no lo dicen de forma expresa, y tal vez deberían hacerlo, necesitamos entender que las facultades de las autoridades laborales mexicanas sólo pueden ejercerse en el territorio nacional, pues de acuerdo con el artículo 42 del ACLAN tienen prohibido desempeñar sus atribuciones en los Estados Unidos o en Canadá.

\section{JÓVENES}

Conforme a un reporte de la OIT que presenta datos de 2008 sobre la ocupación de jóvenes mexicanos ${ }^{56}$ (de áreas urbanas y rurales) entre 15 y 24 años de edad, ${ }^{57}$ el 35\% sólo estudia, el 35\% sólo trabaja, el 10\% estudia y trabaja, y el $20 \%$ no estudia ni trabaja. Esto significa que uno de cada cinco jóvenes mexicanos en edad de trabajar o estudiar no realiza

56 Entendemos por "jóvenes" aquellos individuos que tienen más de dieciséis años, y que por tanto tienen, de acuerdo a la LFT y a la Iniciativa, derecho al trabajo. Véase los artículos 22 y 23 de la LFT. La Iniciativa conserva estas restricciones, y aún crea otras adicionales. Artículos 22, 22 Bis y 23 de la Iniciativa.

57 OIT, Trabajo decente y juventud en América Latina, avance-febrero 2010, Perú, 2010, p. 20. 
ninguna de estas actividades. Aunque estos datos son desalentadores, nos deben hacer reflexionar sobre la forma de atraer a los jóvenes a las aulas y/o al mercado laboral.

La Iniciativa establece una serie de propuestas encaminadas a que los patrones tengan mayores incentivos para contratar a los jóvenes, población típicamente discriminada por su falta de experiencia. ${ }^{58}$ De acuerdo a la exposición de motivos: "Estas propuestas permitirían romper el círculo vicioso en torno a que las personas no tienen empleo porque no están capacitadas y no tienen capacitación porque no cuentan con empleo". La Iniciativa plantea la inclusión de los periodos de prueba por tiempo indeterminado, ${ }^{59}$ los contratos de capacitación inicial ${ }^{60}$ y el trabajo por

58 Bouzas Ortiz, José Alfonso, Régimen contractual, discriminación y situación laboral de la juventud en México, México, Conapred, 2008, documento de trabajo núm. E-03-2008. El capítulo 5 de este trabajo aborda estudios de caso donde se muestran diversas prácticas de discriminación en contra de jóvenes.

59 El artículo 39-A establece el periodo de prueba para las relaciones de trabajo por tiempo indeterminado. A continuación transcribimos el precepto referido: "En las relaciones de trabajo por tiempo indeterminado o cuando excedan de ciento ochenta días, podrá establecerse un periodo a prueba, el cual no podrá exceder de treinta días, con el único fin de verificar que el trabajador cumple con los requisitos y conocimientos necesarios para desarrollar el trabajo que se solicita... Durante ese tiempo el trabajador disfrutará del salario de la categoría o puesto que desempeñe. Al término del periodo de prueba, de no acreditar competencia el trabajador, a juicio del patrón, se dará por terminada la relación de trabajo, sin responsabilidad para éste."

60 El artículo 39-B define el contrato de capacitación inicial en los términos siguientes: "Se entiende por relación o contrato de trabajo para capacitación inicial, aquél por virtud del cual un trabajador se obliga a prestar sus servicios subordinados, durante un periodo determinado bajo la dirección y mando del patrón, con el fin de que adquiera los conocimientos o habilidades necesarios para la actividad para la que vaya a ser contratado. La vigencia del contrato a que se refiere el párrafo anterior tendrá una duración hasta de tres meses o hasta de seis meses cuando se trate de trabajadores para puestos de dirección, gerenciales y demás personas que ejerzan funciones de dirección o administración en la empresa o establecimiento de carácter general o para desempeñar labores técnicas o profesionales especializadas. Durante ese tiempo el trabajador disfrutará del salario de la categoría o puesto que desempeñe. Al término de la capacitación inicial, de no acreditar competencia el trabajador, a juicio del patrón, se dará por terminada la relación de trabajo, sin responsabilidad para éste." Sólo como una precisión técnica, consideramos que es erróneo decir "relación o contrato de trabajo", pues como establece la propia LFT, la jurisprudencia y la doctrina, el elemento constitutivo de la relación laboral es la subordinación y no el contrato de trabajo. 
temporada. ${ }^{61}$ Estas tres figuras permiten que el patrón termine la relación laboral en aquellos casos en los que, luego de haber sido contratados, probados y/o capacitados, los trabjadores no demuestren que son capaces de realizar su trabajo adecuadamente.

Al crear las figuras jurídicas citadas, consideramos que la Iniciativa descuidó un detalle que en la práctica es muy probable que derive en abusos contra el trabajador: el patrón tiene completa facultad discrecional para determinar que trabajadores tienen la "competencia" necesaria para permanecer en el empleo. Consideramos indispensable que la propia ley defina lo que debe entenderse por el término "competencia". De esta manera, la permanencia en el empleo dependería sólo de medidas objetivas y relacionadas con la realización del trabajo desempeñado, y evitaría que los patrones o sus representantes consideraran como causales de incompetencia, y por tanto de rescisión, valoraciones subjetivas e irrelevantes con respecto al trabajador.

Un elemento que no toca la Iniciativa, y que creemos tiene gran importancia en la vida profesional de un joven, es la regulación del servicio social. El servicio social encuentra su fundamento legal en el segundo párrafo del artículo 5o. de la CPEUM, que establece que cada estado determinará cuáles son las profesiones que necesitan título para su ejercicio, las condiciones que deban cumplirse para obtenerlo y las autoridades que han de expedirlo. Al amparo de lo dicho por el texto constitucional, cada estado ha creado una ley reglamentaria que regula, entre otras cosas, lo relativo al servicio social, que es considerado como un requisito con el que debe cumplir el estudiante para obtener su título profesional. En la práctica, e independientemente de lo señalado en las distintas leyes

61 Con respecto al trabajo por temporada, el artículo 39-F dice lo siguiente: "Las relaciones de trabajo por tiempo indeterminado serán continuas por regla general, pero podrán pactarse para labores discontinuas cuando los servicios requeridos sean para labores fijas y periódicas de carácter discontinuo, en los casos de actividades de temporada o que no exijan la prestación de servicios toda la semana, el mes o el año". Hay que señalar que la jurisprudencia ya había reconocido la existencia de la relación de trabajo temporal como una modalidad de la relación por tiempo indeterminado, y en este sentido la Iniciativa sólo incorpora un desarrollo jurídico previo; véase Poder Judicial de la Federación, "Relaciones laborales. Su clasificación conforme a la Ley Federal del Trabajo", tesis aislada, novena época, Tercer Tribunal Colegiado en Materia de Trabajo del Primer Circuito, Semanario Judicial de la Federación y su Gaceta, México, septiembre de 2006, t. XXIV, p. 1527. 
reglamentarias, ${ }^{62}$ el servicio social generalmente consiste en el cumplimiento no remunerado de 480 horas de trabajo. ${ }^{63}$ Aunque este periodo debería de servir a los trabajadores jóvenes como una oportunidad para realizar ciertas labores que posteriormente les ayudaran a integrarse de mejor manera al mercado de trabajo; esto no siempre es así. Muchas veces los jóvenes deben realizar actividades mecánicas y que no guardan una relación directa con su perfil profesional. ${ }^{64}$ Consideramos que una reforma completa a la ley laboral debe establecer ciertas reglas para la realización del servicio social, las cuales, respetando la autonomía que tienen los estados para emitir leyes sobre la materia, aseguren que los jóvenes que presten el servicio social realicen actividades que deriven en su mejor capacitación profesional y obliguen al beneficiario del servicio a pagar una contraprestación mínima para que el prestador pueda cubrir sus gastos de traslado y alimentación. ${ }^{65}$

\section{CONCLusiones}

La Iniciativa propuesta por los legisladores del PAN en marzo de este año tiene como uno de sus ejes rectores el promover la no discriminación. Plantea un marco regulatorio más efectivo y preciso que el que contempla la LFT, especialmente en los rubros que determinan el trabajo de

62 Las distintas leyes reglamentarias establecen, de manera general, que el servicio social deberá prestarse por un tiempo no menor de seis meses ni mayor de dos años. A manera de ejemplo, el segundo párrafo del artículo 55 de la Ley Reglamentaria del artículo 5o. constitucional, relativo al Ejercicio de las Profesiones en el Distrito Federal, así como el artículo 45 de la Ley del Ejercicio Profesional para el Estado de Veracruz de Ignacio de la Llave.

${ }^{63}$ Esto señala, por ejemplo, el Reglamento General del Servicio Social de la Universidad Nacional Autónoma de México en su artículo 6o., que a la letra dice: "El servicio social deberá prestarse un tiempo no menor de 6 meses ni mayor de 2 años y el número de horas que requiera será determinado por las características del programa al que se encuentre adscrito el estudiante, pero en ningún caso será menor de 480 horas...”.

64 La evidencia anecdótica expone casos donde los estudiantes sólo sacan copias, archivan, realizan trámites administrativos y personales de su jefe, etcétera. Véase Sánchez, Cinthya, "Servicio Social ¿requisito o aprendizaje?”, El Universal, México, 1o. de abril de 2006 y Notimex, "Buscará SEP que servicio social sea remunerado", El Universal, México, 26 de febrero de 2008.

65 Independientemente de que esto se cumpla o no, ya es contemplado por algunas leyes reglamentarias, por ejemplo, la del Distrito Federal en sus artículos. 
las mujeres (acoso y hostigamiento sexual), los jornaleros agrícolas, los trabajadores domésticos y los jóvenes. La Iniciativa también contempla el establecimiento de una multa (de 250 a 5,000 veces el salario mínimo general) para aquellos patrones y trabajadores que incurran en cualquier acto o conducta discriminatoria en el centro de trabajo. ${ }^{66}$

Los cambios propuestos en materia de discriminación laboral pueden agruparse en dos conjuntos. El primero contiene aquellas propuestas que enuncian con mayor precisión las medidas protectoras ya contempladas implícitamente en la LFT; esto es, las que se infieren a partir de la interpretación de algunos de sus artículos, o bien que son de aplicación supletoria por referencia a algún instrumento internacional. Pensamos que estos cambios son benéficos en dos sentidos: primero, evitan interpretaciones incorrectas que podrían tener las autoridades laborales al resolver este tipo de asuntos, y que en gran medida derivan de la falta de claridad o de la inclusión de un mandamiento expreso en la ley; y segundo, evitan los errores que las mismas autoridades podrían tener debido a su ignorancia de las leyes reglamentarias y los tratados internacionales en la materia. El segundo conjunto contiene innovaciones al ordenamiento laboral, tales como las medidas relativas al acoso y hostigamiento sexual, así como al trabajo de los jóvenes. Aunque estas propuestas admiten ciertas críticas, creemos que impactarían de forma positiva las condiciones de los trabajadores en caso de que la Iniciativa fuera aprobada.

Si bien reconocemos que ésta constituye un avance en materia de regulación de la discriminación laboral en nuestro país, también tiene varias debilidades u omisiones, las cuales se apuntan a continuación.

La Iniciativa no considera la creación de normas que protejan de manera expresa el trabajo de ciertos grupos que tienden a ser discriminados, como los extranjeros, los miembros de minorías religiosas, personas con preferencias sexuales distintas o indígenas que laboran en zonas urbanas. Aunque la LFT y las demás leyes reglamentarias prohíben, implícitemente, conductas discriminatorias en contra de estos trabajadores, la Iniciativa no incorpora al cuerpo del texto disposiciones al respecto. Tal omisión constituye una deficiencia de la misma, máxime a la luz de que muchas de sus propuestas en materia de discriminación son, precisamente, incorporaciones de preceptos contenidos en tratados internacionales o en leyes reglamentarias. 
Otra debilidad es la inclusión de diversas prerrogativas que para ser ejercitadas requieren de la anuencia del patrón, lo que no sólo constituye un atentado al espíritu del derecho laboral, ${ }^{67}$ sino también al propio concepto de trabajo decente, elemento fundamental de la Iniciativa. Por ejemplo, para que una madre trabajadora pueda trasladar semanas de descanso previo al parto para después del mismo, se requiere la autorización del patrón. Particularmente peligrosas resultan las atribuciones concedidas al patrón en la relación de trabajo de capacitación inicial y en el periodo de prueba, donde se señala que éste tendrá completa discreción para determinar si el trabajador posee la "competencia" requerida para permanecer en el empleo.

La Iniciativa no contempla la recisión de la relación laboral para aquellos trabajadores que cometan conductas discriminatorias en el lugar de trabajo. La omisión de un precepto de esta naturaleza es conspicua, sobre todo considerando que se incorpora como causal de rescisión el hostigamiento o acoso sexual por parte del trabajador en contra de cualquier persona en el lugar de trabajo.

La preparación de las autoridades laborales en materia de discriminación es un asepecto poco atendido por la Iniciativa. Como hemos dicho, la LFT vigente prohíbe la discriminación, e incluso una interpretación armónica de sus artículos a la luz de lo que establecen los tratados internacionales en la materia podría llevarnos a concluir que muchos de los preceptos planteados por la Iniciativa son innecesarios. Pero si esto ocurre, ¿por qué el tema de la discriminación laboral es tan poco conocido por nuestras autoridades laborales? Pensamos que, en parte, esto se debe a que tales autoridades desconocen el marco legal aplicable (tanto nacional como internacional). Al respecto, consideramos que otra deficiencia de la Iniciativa es que no establece que los funcionarios de las Juntas ${ }^{68}$ deban tener alguna preparación especial en materia de discriminación para poder ocupar sus respectivos puestos.

67 No olvidemos las palabras de Mario de la Cueva, quien señaló que uno de los caracteres del derecho del trabajo es el ser un derecho de la clase trabajadora. Véase Cueva, Mario de la, El nuevo derecho mexicano del trabajo, 21a. ed., México, Porrúa, 2007, cap. IX.

68 En términos de lo señalado por la Iniciativa, nos referimos a secretarios, funcionarios conciliadores, auxiliares, secretarios auxiliares, secretarios generales, representantes y presidentes. 
En conclusión, la Iniciativa todavía es perfectible en muchos aspectos. Si se debate en el Congreso de la Unión, los legisladores deben poner particular atención al análisis de la parte relativa a la discriminación laboral, y pugnar por ciertas adecuaciones congruentes con lo que aquí se ha dicho.

C 